\title{
Contact Urticaria to Giraffe Hair
}

\author{
Thomas Herzinger Eva Scharrer Marianne Placzek Bernhard Przybilla \\ Klinik und Poliklinik für Dermatologie und Allergologie, Ludwig-Maximilians-Universität, München, Deutschland
}

\section{Key Words}

Animal allergens $\cdot$ Contact urticaria $\cdot$ Giraffe .

Occupational allergy

\begin{abstract}
Background: Immediate-type hypersensitivity to animal proteins is a common problem in people occupationally exposed to animals. Methods: A 19-year-old female working as a voluntary zookeeper in her off-time suffered from hives on her forearms following contact to the fur of a giraffe. For diagnostic evaluation, skin prick tests, assessment of specific serum IgE antibodies, and basophil activation tests were performed. Results: Skin prick tests with a standard series of common aeroallergens were positive for various pollens. Prick testing with native materials was positive for extracts of hair from two different giraffe subspecies in the patient, but not in control subjects. By CAPFEIA, no specific serum IgE antibodies to dander of a large variety of animals were found in the patient. In the basophil activation test, expression of the activation marker CD63 was induced by extract of giraffe hair on the cells from the patient, but not on those from unaffected controls. Conclusions: This patient suffers from an 'exotic' immediate-type contact allergy to giraffe hair.
\end{abstract}

Copyright $\odot 2005$ S. Karger AG, Basel

\section{Introduction}

Development of immediate-type, IgE-mediated allergy to animal proteins is a common occurrence in persons occupationally exposed to animals, reactions manifesting as ocular, respiratory and cutaneous symptoms [1-3]. Asthma has been reported in zoo workers, veterinarians, laboratory personnel, animal farmers and hunters upon contact to cat, dog, rat, mouse, hamster, horse, cattle, pig, sheep, goat and deer [3-5]. Approximately one third of the workers having contact with laboratory animals will develop allergic asthma or skin disease [6]. In a questionnaire study of Californian veterinarians, $20 \%$ of the responders reported animal-related skin symptoms, $60 \%$ of them experienced work-related rhinitis and $43 \%$ work-related pulmonary symptoms like cough, wheezing, chest tightness or shortness of breath [7]. Although contact urticaria is more rarely seen than respiratory symptoms, cow dander was the prime cause of occupational contact urticaria in Finland, topping even natural rubber latex [8, 9]. In Germany, contact urticaria has also been reported in hunters as a consequence of contact to deer meat or hair [10-14]. Here we report the unusual case of an animal handler who suffered from contact urticaria to giraffe hair.

\section{KARGER \\ Fax +4161306 1234 E-Mail karger@karger.ch} www.karger.com www.karger.com/iaa
Correspondence to: Dr. med. Thomas Herzinger

Klinik und Poliklinik für Dermatologie und Allergologie, Ludwig-Maximilians-Universität Frauenlobstrasse 9-11, DE-80337 Munich (Germany)

Tel. +498951606388, Fax +498951606389

E-Mail Thomas.Herzinger@lrz.uni-muenchen.de 


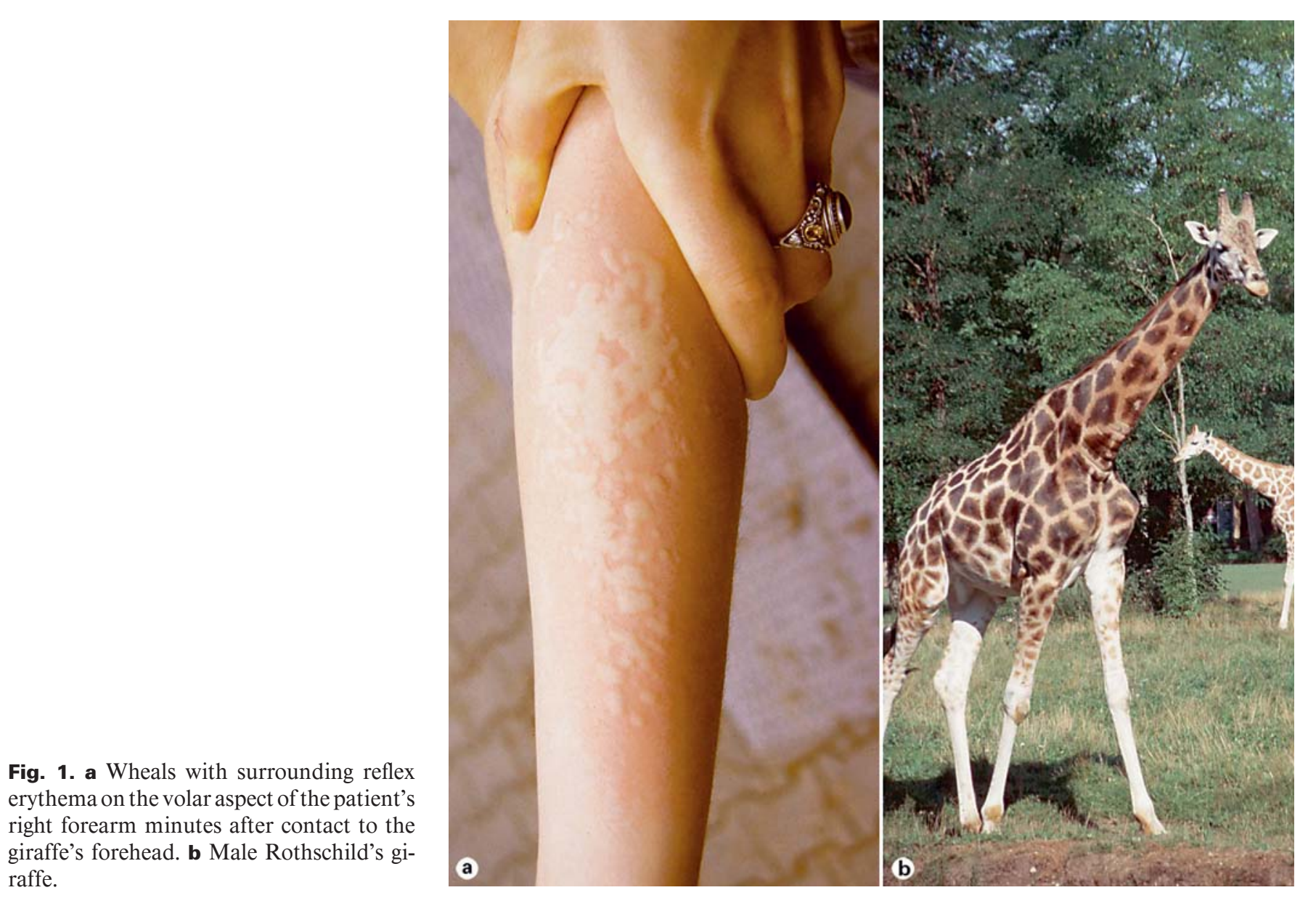

\section{Case Report}

\section{History}

A 19-year-old student used to work as a voluntary keeper at a municipal zoo on weekends and during her vacations. After 2 years, itching and wheals on her forearms started to develop within minutes after petting the head of a male Rothschild's giraffe (Giraffa camelopardalis rothschildi; fig. 1). Wheals resolved spontaneously after 1-2 h. This occurred regularly upon contact with the giraffe's fur independently of the season. There were no concomitant nasal, ocular or respiratory symptoms. Skin contact with other animals, e.g. bison, zebra, goat, ibex or elephant, was tolerated without any symptoms, as was contact to the giraffe's forage. The patient had a history of allergic rhinoconjunctivitis from April to May. She reported minor oral itching to nuts, almonds, apples, nectarines and avocado.

\section{Allergological Assessment}

Immediate-type skin prick tests with a standard series of common aeroallergens revealed $4+$ reactions (wheal diameter $>6 \mathrm{~mm}$ ) to grass, rye and birch pollen, $3+$ reactions (wheal diameter $>4 \mathrm{~mm}$ ) to hazel pollen and $2+$ reactions (wheal diameter $3 \mathrm{~mm}$ ) to numerous further pollens. A standard extract of horse dander induced no skin prick test reaction. For giraffe-specific prick tests, extracts were prepared by suspending $30 \mathrm{mg}$ of hair from the forehead of a Rothschild's giraffe (G. camelopardalis rothschildi) or a reticulated giraffe (Giraffa camelopardalis reticulata), respectively, in $1 \mathrm{ml}$ of phosphate-buffered saline, followed by sonication twice for $10 \mathrm{~s}$ at $80 \%$ amplitude with a IKA U50 homogenizer (IKA Werke, Staufen, Germany). Hair specimens were collected in October to preclude possible contamination with pollen allergens. Skin prick tests with both extracts induced $2+$ reactions.

Assessment of the patient's serum by CAP-FEIA (Pharmacia Diagnostics, Freiburg, Germany) revealed specific IgE antibodies to birch pollen (CAP class 4), rye, alder, hazel, beech and oak pollen (each CAP class 3), and ragweed and ribwort pollen (each CAP class 2). No specific serum IgE antibodies could be detected to allergens from cat, dog, horse, cattle, guinea pig, mouse, rat, goat, sheep, rabbit, pig or golden hamster. Total IgE was $111 \mathrm{kU} / 1$ (normal range $<100 \mathrm{kU} / \mathrm{l}$ ).

Allergen-induced activation of basophils was determined by flow cytometry (Basotest; Orpegen Pharma, Heidelberg, Germany). An extract of Rothschild's giraffe hair prepared as described above was incubated with heparinized whole blood from the patient and from 3 controls. These controls had no history of allergy to animal allergens. Cells were double stained with a phycoerythrin-conju- 


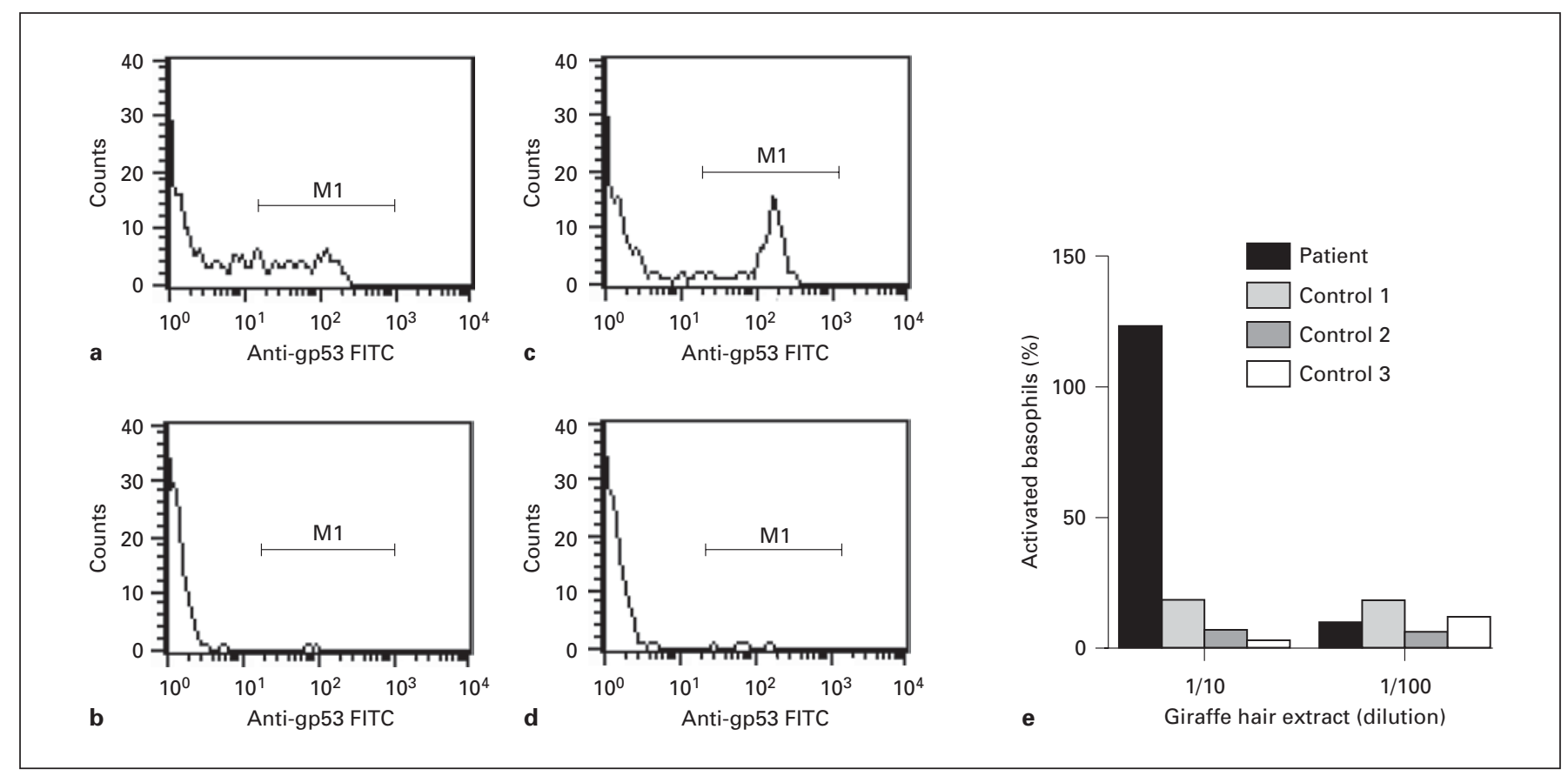

Fig. 2. a-d Activation of basophils after incubation of blood from the patient with a positive control [a, N-formylMet-Leu-Phe (fMLP)], with a negative control (b, Basotest stimulation buffer) or with the extract of Rothschild's giraffe hair at concentrations of 1:10 (c) or 1:100 (d). e Activated basophil granulocytes from the patient and 3 unaffected controls. $\%=$ Percentage of fMLP-activated basophils.

gated antibody to human IgE (identifying basophil granulocytes) and a fluorescein-conjugated antibody to glycoprotein gp53 (CD63) expressed on activated basophils. Cell characteristics were determined by flow cytometry (FACScan, Becton-Dickinson, San Jose, USA). Following exposure to giraffe hair extract at various concentrations, the percentage of activated basophils was 4- to 10-fold higher with cells from the patient compared to cells from the controls (fig. 2).

\section{Discussion}

Giraffes belong to the family Giraffidae, which comprises only the species giraffe (G. camelopardalis) and okapi (Okapia johnstoni). Together with the Bovidae (including, among others, cattle, bison, ibex, goat and sheep) and the Cervidae (including various deer species), the Giraffidae belong to the infraorder Pecora. There are nine recognized subspecies of giraffes, which are distinguished by their coat pattern and geographical distribution. Taxonomically, deer and cattle are the most closely related animals which have been reported to cause contact urticaria. Cross-reactivity to allergens from deer and cattle has been demonstrated $[15,16]$. Our patient neither re- acted to contact with other Pecora species nor did she show specific IgE to other Pecora species. She only reacted to hair/dander from two different Giraffa subspecies, suggesting a species-specific allergen.

The basophil activation test is based on the demonstration of a membrane protein marker that appears due to exposure to allergens $[17,18]$. The basophil activation assay can be particularly helpful when assessing reactions to rare allergens for which routine diagnostic tests such as measurement of specific serum IgE antibodies are not available. The absence of positive test results among controls and the positive correlation with cells from the patient to her history and with the results of the prick test further support the diagnosis of allergy to giraffe allergens.

Our patient exhibited sensitization to multiple pollen species, and there was initial concern that the skin symptoms might be caused by pollen caught in the animal's fur. However, we believe this to be unlikely since (i) her usual reaction to pollen was rhinoconjunctivitis and not urticaria, (ii) hair specimens from the giraffes for the test extracts were collected in October, i.e. outside the pollen season in Germany, (iii) the patient's skin symptoms showed no seasonal predilection, and (iv) petting other 
zoo animals was tolerated without symptoms. However, respiratory atopic disease, as present in our patient, is a known risk factor for acquiring an immediate-type allergy against animal antigens [7]. The giraffe should be added to the list of potential allergen sources in animal workers.

\section{Acknowledgment}

We thank G. Weimer for skilled technical assistance, Prof. Dr. H. Wiesner, Münchner Tierpark Hellabrunn (www.zoo-munich. de), for providing reticulated giraffe hair, and Dr. B. Jantschke, Zoologischer Garten Augsburg (www.zoo-augsburg.de), for providing hair from and the photograph of a Rothschild's giraffe.

\section{References}

1 Susitaival P, Husman L, Hollmen A, Horsmanheimo M, Husman K, Hannuksela M: Hand eczema in Finnish farmers. A questionnaire-based clinical study. Contact Dermatitis 1995;32:150-155.

2 Bush RK, Wood RA, Eggleston PA: Laboratory animal allergy. J Allergy Clin Immunol 1998;102:99-112.

3 Cockcroft A, Edwards J, McCarthy P, Andersson N: Allergy in laboratory animal workers. Lancet 1981;i:827-830.

4 Slovak AJ, Hill RN: Laboratory animal allergy: a clinical survey of an exposed population. $\mathrm{Br}$ J Ind Med 1981;38:38-41.

5 Bardana EJ: Occupational asthma and related conditions in animal workers; in Bardana EJ, Montanaro A, O'Hollaren MT (eds): Occupational Asthma. Philadelphia, Hanley \& Belfus, 1990, pp 225-235.

6 Gordon S: Occupational sensitization to laboratory animals. Clin Exp Allergy 1997;27:603605 .
7 Susitaival P, Kirk J, Schenker MB: Self-reported hand dermatitis in California veterinarians. Am J Contact Dermat 2001;12:103-108.

8 Kanerva L, Susitaival P: Cow dander: the most common cause of occupational contact urticaria in Finland. Contact Dermatitis 1996;35: 309-310.

9 Kanerva L, Toikkanen J, Jolanki R, Estlander T: Statistical data on occupational contact urticaria. Contact Dermatitis 1996;35:229-233.

10 Geyer E, Kränke B, Derhaschnig J, Aberer W: Contact urticaria from roe deer meat and hair. Contact Dermatitis 1998;39:34.

11 Spiewak R, Dutkiewicz J: Allergic contact urticaria and rhinitis to roe deer (Capreolus capreolus) in a hunter. Ann Agric Environ Med 2002;9:115-116.

12 Reiche L: Venison contact dermatitis. Australas J Dermatol 2002;43:72-73.

13 Ng TP: Occupational asthma caused by orangutan in a zoo animal handler. Singapore Med J 1998;39:127-128.
14 Amrol DJ, Georgitis JW, Dunagan DP: Anaphylaxis to deer dander in a child: a case report. Ann Allergy Asthma Immunol 2000;85:372373.

15 Spitzauer S, Valenta R, Muhl S, Rumpold H, Ebner H, Ebner C: Characterization of allergens from deer: cross-reactivity with allergens from cow dander. Clin Exp Allergy 1997;27: 196-200.

16 Nahm DH, Park JW, Hong CS: Occupational asthma due to deer dander. Ann Allergy Asthma Immunol 1996; 76:423-426.

17 Sanz ML, Maselli JP, Gamboa PM, Oehling A, Dieguez I, de Weck AL: Flow cytometric basophil activation test: a review. J Investig Allergol Clin Immunol 2002;12:143-154.

18 Sainte-Laudy J, Sabbah A, Drouet M, Lauret MG, Loiry M: Diagnosis of venom allergy by flow cytometry. Correlation with clinical history, skin tests, specific IgE, histamine and leukotriene C4 release. Clin Exp Allergy 2000;30: 1166-1171. 